\title{
Principles of Participatory Teaching Methods on Management Science
}

\author{
Jiangquan Huang \\ School of Business Central South University of \\ Forestry \& Technology \\ Changsha, China \\ hjq1723@163.com
}

\author{
Chunfeng Wang \\ Department of Clinical Medicine,Huaihua Medical \\ College \\ Huaihua, China \\ hndx1088@163.com
}

\begin{abstract}
Management science is a course showing such characters as basic、theoretical and abstract.It is difficult for university freshmen to understand the principles and concept of management science. Furthermore, teachers take Cramming teaching, the effect of management teaching is not very good. And so, we should advocate the model of management teaching, including respecting students' subject status, and following five basic ideas as the transformation of teaching idea, stimulation of learning interest, the normal practice activities, the embodiment of the teaching materials, the construct of teaching atmosphere. Tried to attract the student to participate in the teaching for themselves rather than as an observer.
\end{abstract}

Keywords participatory teaching; principles;management science;student main body

\section{INTRODUCTION}

Management science is a necessary course opened for majors in many of our institutions of higher learning.It can be interpreted by the practical implication for the importance of the teaching position on management. As Peter-Drucker,the famous American management expert, put it, " In human history, very few of what more rapidly than the emergence and development of the management,has a more significant and more tense impact on humankind. " Because it is both a science and an art, to master management is not easy. There is a certain degree of difficulty for teaching activities of management. On the one hand, it comes from scientific rigor and artistic performance of "It can be felt but not explained" in the arena of management. On the other hand, it lies in the freshmen to whom the course be teached. With few managerial recognizations both in rational and perceptual perspectives, our freshmen often fail to achieve the teaching goal named "both to give fish and to give fishing", that is ,grasp both the managerial theory and practice. As such, it is necessary for teachers to combine closely the characteristics of the course and characteristics of students, to explore and sum up constantly the teaching mode of management course in order to improve its teaching quality.

However, with the shackles of traditional teaching philosophy, there is a serious problem divorced from the teachers' teaching and student's learning. Even some teachers only teach student according to the script book, so that many students completely have no interest in class. The due process of integration between teachers and students is easily replaced by that of isolation and confrontation, with exception of some teachers' organizing disciplined classes which comprise the absence of students' dominant position and the resultant limited effect. Therefore, how to improve students' learning and how to use correctly student's roles in order to achieve teacher-student integration? In our opinion, according to our teaching experience in school and training experience in corporation, it is a effective solution for students to participate in teacher-led class to achieve the desired teaching effectiveness. In this paper, the theoretical foundation and design principles of participatory teaching and learning in management course are discussed, which provide some inspiration for majority of teachers in management as well as other categories of curriculum teaching in the use of participatory teaching idea and method to improve teaching effect.

\section{POINTS OF VIEW AND THEORETICAL BASISES OF PARTICIPATORY TEACHING AND LEARNING}

The teaching mode of "participation" originated in Britain. Initially, it was not a teaching method, but a set of sociological theory summarized by British sociologists when they did some international aid researches overseas. The theory is that only makes the local people to maximize participation in aid projects ,to make aid project a success. This is similar to China today's poverty alleviation by providing science and technology ,education and training into practice instead just donations. Only in this way, the poor will be actively involved in helping deficient up to but not returning to poverty. Later, some scholars apply the theory to the field of education and teaching, and gradually formed its own system of " participatory " teaching. Its essence is to let students participate in the teachers' leading teaching projects instead acting as a passive bystander role, and to allow students to truly experience the real intellectual inquiry of the novel, twists and turns and wonderful, so that the student has infinite participation motivation and desire in classroom teaching projects organized by the teacher. The goal of participatory teaching is cultivating students' competence of self-solving the various problems encountered in the study through discussion, asking questions, and after class to find information, social surveys and so on. Undoubtedly, once this interest in learning of the student is aroused, the teaching of the teacher will get a 
multiplier effect. With the endless curiosity for knowledge, the purpose of higher education is training students to explore the mysteries of knowledge, to enrich the knowledge structure, and to improve their abilities to apply knowledge. The difference in nature of a good teacher and a bad teacher lies in whether to address the essence of the learning needs of students to school and to use the scientific and reasonable method to guide, stimulate the demand. As Markov put it, when pedagogy comes into students' emotional and will and touches on students' psychological needs, this kind of teaching will become highly effective.

On the contrary, in the area of corporate training, due to the interested materials and different approaches selected by corporate trainer, a entirely different training effect comes into being, such as the tutor designed a number of teacherstudent interaction, students interaction, interaction between men and women, leadership and subordinate interactive link, created an atmosphere for students to ask questions, and encouraged students to question, to self-exploration and self-summary finally, so that participants took the floor in the classroom, asked questions and cooperated with teacher training programs earnestly carried out. Such a training process made both teachers and students feel receipts. The biggest difference between this sort of training and some teaching of our teachers in the classroom is allow students to participate in the activities, so that it can be kooked into the eyes as well as the mind of students and enables them to obtain knowledge of the pleasure and satisfaction experience in participating in the initiative.

Well-known educator in the United States Dewey once said, if he (the student) can not be planning his own solution to the problem and find their own way out ,his schooling will be a failure. Even if he can recite some correct answers, the answers to these questions is $100 \%$ correct, he still fail to learn. Similarly, participatory teaching and learning is advocated by students' active participation to the planning of the solutions to the relevant problems, in order that the student can get real experience of self-solve to find solutions to problems and access to knowledge of the fun as well as achievement.

The main theoretical basis for participatory teaching are cooperative theory and constructivist theory. Cooperative learning is that students in a group or team in order to complete common tasks, with clear division of responsibilities of mutual aid learning. It includes five basic elements. That is: 1 . Positive mutual support and cooperation, in particular, face to face to promote interaction; 2. Positive commitment to personal responsibility to complete the common task; 3. expect all students to communicate effectively, establish and maintain mutual trust between the team members to resolve conflicts within the group; 4 . for each task group processing; 5 . to assess the effectiveness of the joint activities and to seek ways to improve its effectiveness. Such can be summarized as follows: positive dependence, personal responsibility, social skills, mixed grouping and group self-assessment. Cooperative learning is not a strict relationship between teachers and students in opposition, not a kind of mutual intersected relationship, but a partnership and integration relationship. The status establishment of such relationship lies a good foundation for closing distance between teachers and students, equal dialogue, mutual discussion and complement of teaching, and studying the atmosphere of common progress. At the same time, during the study, the cooperation among the students and joint completement of the learning tasks are of great significance to develop the abilities of students' teamwork, communication and expression, organization plan, leadership and control to which are related the principle of management. Also, it is important to student's subsequent work as well as promotion, and development of the whole society. As Dr Yang Zhenning pointed out, if a person in the past may be independently finish the work for Nobel Prize, since the 1980s, in particular, into the information society, no people to participate in and no cooperate with each other, there is impossible for any significant invention to come into being. The constructivists think the world is objective existence, but each person for world understanding and meaning is not the same. Everyone is based on their own experiences to construct the reality, or to explain the reality. But the personal experience of the world is created in their own minds. Because everyone's experience and and the experience of different beliefs, people have different understandings of the outside world. Therefore, constructivism trying to solve a series of adverse consequences in the actual teaching of behaviorism and cognitive school, that is ,too much emphasis on understanding the learning objectivity. Constructivism are more concerned about how the original experience, mental structures and beliefs as a basis for building understanding of the world and knowledge on the world. Then, where are the original experience, mental structures and beliefs come from? They believe that through the activities for the students' active participation is the source of individual experience of the world, is the source of individual expression of the meaning of things. In the classroom teaching, educational activities for student development is initially external activities, but due to the participation of students' own intelligence to participate in, the external activities are internalized into the psychological process of the main body and produce the main body of the individual experience. That is the basic theory of self-construction why we advocate to allow students to participate in teaching. In short, constructivism emphasizes the builders to use their existing knowledge, experience and capabilities of the external perception of things through a series of specific activities or skills into individual self of all things. And the difference among the school of cognitive, behavior, constructivism is that the constructivism can transform the outside into the inner self. As such, participatory teaching and learning is to actively guide the students through a series of links, measures forms and means to participate as a real subject and to their own knowledge, experience in construction of new knowledge and experience in system. As a article authored by Xiao Chuan The true meaning of education: the value of guidance and freedom construction put it, the true meaning of education is the value guide and self-construction of the 
united. From the student's growth process, education is a unity of waked spirit, potential, spacious inner and the uniqueness. Also, from the point of view of teacher-student activities, it is the experience of sharing the vision of integration and the inspiration of the soul.

\section{PRINCIPLES INVOLVED IN PARTICIPATORY TEACHING}

According to the source and characteristics of participatory teaching and learning theory, as well as some specific experience in teaching, we consider that the teaching-principle of the following aspects should be emphasized.

\section{A. Comprehensiveness}

The principle of comprehensiveness requires students in the learning process not only pursuit a one-side grow, but also develop all-round. It is a common decision required by individual self-development, social development of student's comprehensive quality, as well as self-demands of systematic knowledge in the teaching process. Departing from the doctrine of Marxism on man's all-round development theory, we recognize that human development is actually the human unity of free development and comprehensive development, also the unity of individual original and free development. Participatory teaching promote students to develop various scientific and cultural qualities, moral and psychological quality, rather than on the one-side development. This also determines diversity's nature of participatory teaching. Such methods strive to enhance students quality rather than volume, to promote students' self consciousness and inner wisdom. On benefit of students, there are active learning attitude, good psychological quality influenced by process of acquiring basic knowledge and basic skills, correct choice of value, a sense of social responsibility, and finally the goal of learning how to learn, how to survive and how to make all-round developed. Undoubtedly, as the practice of promoting the comprehensive self-construction, classroom teaching is bound to concern the principal to participate in classroom teaching mode, to concern the comprehensive developed of the individual quality.

\section{B. Full participation}

As early as the time of Confucius, the education is to promote the educational activities for all students, that is anyone should get an education and there is no un-teachable students but unsuitable teachers. The teacher will not teach mainly because they do not understand enough the plasticity of the student and are lack of forceful guidance. To this end, educators advocate teachers for all students to take different ways to be guided, so that their endowment and potential can be comprehensively developed. According to "Basic Education Curriculum Reform Program(Trial)”, we should create an environment for students to actively participate in class teaching, stimulate the learning enthusiasm of the student, train students' ability for mastering and applying knowledge ,so that every student can be fully developed. As the famous educator Sukhomlinski said, there was not a person who was absent of talent inherently and the problem was that educator should find every student's endowments, interests, hobbies and expertise, in order to provide sufficient conditions for their performance and development and proper guidance. The objective individual differences of students and the uniqueness of every student, is a real problem that we have to face in the course of actual teaching. Thus, the teachers should get a specific understanding of each student's learning condition for a differential treatment and design a variety of different levels of activities as well as problems for meeting the needs of students at different levels. As Rousseau put it in Open the door to nature, each of the human mind has its own form, we should guide him through its own form, but not educate him through other means, in order that the what you have done succeed. For example, some students are good at verbal communication, some good at written expression, some better than planning, and some willing to serve, and some good at leadership. All this requires teachers to engage students in classroom teaching through various forms of activities or evaluation to stimulate students' interest and to fully tape the unique potential of the students, so that the student have a good training and upgrading in stead of some students of concentration and some others of standing-by, which widening the gap of teaching results they have achieved at the same educational environment.

\section{Full guidance}

Full guidance refers to teachers always act a leader in the role of organization inside and outside the classroom teaching, to teachers guide and stimulate students's interest in learning and autonomy by means of planning lessons, designing teaching forms, and evaluating teaching effectiveness, and to teachers intervene minimally students's learning, respect for the dominant position of students and really establish a "student-centered teaching philosophy". To this end, teachers should implement the "five changes" in the classroom teaching: the main changes from the teachers to teach to students to learn; from teacher-centered into a student-centered; the transition from one-way propagation to two-way communication; mainly from teachers organized the teaching-oriented to students selfcontrol; the main change from imparting knowledge to focus on the mental skills development and comprehensive promotion.

\section{Full process}

Full process means that the teacher, through the whole process of participatory teaching and learning, should organize and plan the teaching activities including content, methods, means and evaluation in order to meet the actual needs of students. However, scholars statistics indicate that in the traditional management teaching process, $65 \%$ of students think that the "traditional teaching materials are too stiff and lag"; about $78 \%$ of students require "strengthening of traditional Chinese management thought"; more than $80 \%$ of students ask teachers for lecture on "Management latest developments"; $88.4 \%$ of college students require teachers to adopt the "teacher-student interaction in class 
discussion method"; more than $90 \%$ of students require teachers "should not take the chalk-talk teaching methods"; $93 \%$ of college students want to use the "Case Study" of methods; $65.8 \%$ of students ask teachers to reduce the traditional teaching methods on copy; $74 \%$ of students require teachers to use the "multimedia teaching"; $87 \%$ of college students want "management practice experts to give lectures" and “ organizing students to investigate companies" ; 79\% of students demand "the proportion of the final test scores should be reduced".

All of these issues reflect aspects of the update requirements to better meet students' learning needs. In the design of classroom teaching, the teacher should monitor the entire process to reflect the needs of students into every step. Only in this way can students be attracted to actively participate in every aspect of active learning.”

\section{E. Teamwork}

On the basis of the teamwork, the student are divided into a variety of study groups, the tasks assigned by the teacher are completed in terms of a series of sub-group, which always reflect the learning organization, teamwork and cooperation, also always decided by social and group learning of individual as well as systematic learning task. The facts indicate that the effect of students' learning exposed to a team and collective study is better and much more obvious than that of individual alone, and also is more popular to the student. Based on it, corporate training is frequently used in the team to expand. "Participatory" classroom teaching program by teachers is to determine open topics, scientific group, the group within the division of labor, and as a team to complete social research, data collection, and then form a consensus and represented in the group discussion-class exchange and other aspects of composition. In fact, the process of students participating in teaching is a cooperation process of student-student and teacher-student. of course, the cooperation is a division of labor organizations and exchanges of both students interaction, teacher-student exchanges and students of social practice. In our organized group negotiations, it was generally in terms of voluntary groups. However, we often put forward specific requirements on the group and such characteristics as the degree of each group in the number of students, gender, learning and so on will be taken into account. In this way, the phenomenon of "cold field" does not appear in the course of discussion in a group and the situation of "one-man speaking" is also avoided, so different levels of the entire class of students in this way can participate in the classroom and achieve the overall effectiveness of training. Not only do the student develops capabilities of cooperation and communication, but also mobilize the enthusiasm for every student's sense of participation and learning. Therefore, cooperative learning is useful to the cultivation of students' social awareness, also helpful for students to appreciate their own worth and feel each other's respect, so that inspire greatly student's enthusiasm of team learning and knowledge discussion as well as capacity-building. As such, the participatory teaching of team-cooperation is one of the most effective ways of participation teaching..

\section{REFERENCES}

[1] G. Yuan yuan,Chen qian Teaching Method Innovation of Management Journal of Southwest University for Nationalities, Humanities and Social Science Edition, vol.10, 2003.pp.36-38

[2] Wang tan. Cooperation Learning Theory. Beijing: Press of Education and Science,1994

[3] Song nai qing. Ideas and Innovation of the New Basic Education Curriculum in China. Beijing: China Personnel Publishing,2002

[4] MOE, China. Outline of Concept of Quality Education. Beijing: San Lian Publishing,2001

[5] Zhang zhi yong. Innovation and Education: The Transformation of the Educational Paradigm. Jinan: Shangdong Education Publishing, 2004.

[6] Yao guo rong, Lu lin.Reform and Research on Management Classroom Teaching. Statistics Education,vol.3, 2007. pp.35-36. 